Research Article

\title{
Pattern of prescription and drug use in psychiatry out patient department of private practitioners of Central India
}

\author{
Chetna A. Shamkuwar ${ }^{1 *}$, Ashish D. Chakravorty ${ }^{1}$, Meena P. Shrivastava ${ }^{2}$, Ragini Deshmukh ${ }^{3}$
}

${ }^{1}$ Department of Pharmacology, Government Medical College \& Hospital, Nagpur, Maharashtra, India

${ }^{2}$ Department of Pharmacology, ${ }^{3}$ Medical Officer, Indira Gandhi Government Medical College, Nagpur, Maharashtra, India

Received: 27 September 2013 Accepted: 8 October 2013

\section{*Correspondence to:}

Dr. Chetna A. Shamkuwar, Email:

chelsycosmos@rediffmail.com

(C) 2013 Shamkuwar CA et al. This is an open-access article distributed under the terms of the Creative Commons Attribution Non-Commercial License, which permits unrestricted non-commercial use, distribution, and reproduction in any medium, provided the original work is properly cited.

\begin{abstract}
Background: Psychotropic drugs have had a remarkable impact in psychiatric practice. The continuous monitoring of prescription and drug utilization studies may help to identify the problem involved in therapeutic decision and promote rational prescribing. Very few studies from India have evaluated the prescription pattern of Psychiatrists. Present study was undertaken to analyze the prescription pattern and drug used in psychiatric Out Patients of private practitioners of Central India.

Methods: One thousand prescriptions were collected by undergraduate students from chemist and analysed. Study parameter like demographic profile of patients viz. age, sex, diagnosis were recorded. Basic drug indicators, the prescribing pattern of antipsychotics and other categories of drugs were also recorded. The most common and, top brands of anti psychotics were analyzed .Inappropriate prescription if any were recorded and analyzed further.

Result: The most common psychotropic drugs were anti-anxiety in $361(36.1 \%)$ and antidepressants $130(13 \%)$ prescribed for various psychiatric disorder. Usage of Sedative Hypnotics 104(10.4\%), anti-psychotics 90(9\%) and anticonvulsants $80(8 \%)$ drugs in prescriptions. The incidence of polypharmacy $(22 \%)$ was common occurrence in prescriptions. The commonest combination prescribed was of tricyclic antidepressant with benzodiazepines. Central anticholinergic was commonly prescribed with anti psychotics.

Conclusions: Anti-anxiety drug (benzodiazepines) was the most frequently prescribed class of psychotropic drugs in various psychiatry disorders. The prescribing prevalence of Alprazolam with different brand names was more than that of other benzodiazepines. The combination of different psychotropic drugs were also prescribed.
\end{abstract}

Keywords: Prescribing pattern, Private Practitioner, Psychotropic, Antipsychotics, Antidepressants

\section{INTRODUCTION}

Psychiatric disorders are common in medical practice and may present either as a primary disorder or a co-morbid conditions.

Depression occurs frequently in patients with neurological disorders particularly cerebrovascular disorders, Parkinson's disease, dementia, multiple sclerosis and traumatic brain injury, diabetes mellitus, hypothyroidism, cancer etc. HIV is frequently associated with features of depression, most commonly depressed mood and memory impairment. ${ }^{1}$ Mood disorders may also be secondary to chronic administration of specific medication like antihypertensives. ${ }^{2}$
Studying prescription pattern provides opportunity to monitor therapeutic trends. Many studies from western countries have reported prescription pattern of various psychotropic medication. These studies have looked into national prescription patterns ${ }^{3}$, age and gender difference in antipsychotic prescription. ${ }^{4}$

Setting standards and assessing quality of case through performance and review should become part of everyday clinical practice. ${ }^{5}$ The recent proliferation of new drugs, their widespread use and powerful action, the rising recognition of immediate and delayed adverse effects and rising concern about the cost of drug have stimulated a new interest in the manner in which physician prescribe drugs. ${ }^{6}$ 
In developing country, almost all psychotropic medications available world wide are readily available in India. However, very few studies from India have evaluated prescription patterns of Psychiatrists. Some studies which have evaluated antipsychotic prescription pattern in India are limited by sample size. ${ }^{7,8}$ Hence present study was undertaken to analyze the prescription pattern and drugs used in psychiatric Out Patients of private practitioners of Central India.

\section{METHODS}

This study was carried out at tertiary care hospital. Prescriptions were collected from chemist at different point of central India for a period of 4 month. Data of 1000 patients were collected by IInd year MBBS students, as a part of ongoing research project. The prescriptions were studied for one encounter. The prescriptions were analyzed on the basis of following parameters

1. Demographic data

2. Diagnosis

3. Number of drugs per patients

4. Duration of therapy

5. Fixed dose combinations

6. Any advice given to the patients

The study protocol was approved by institutional Ethics Committee. The data was analysed by simple proportion.

\section{RESULTS}

Total 1000 prescriptions were studied. Out of which diagnosis was mentioned only in 396 prescriptions.

Table 1: Depicts demographic profile of the patients. Total demographic profiles for 537 patients were recorded from the prescriptions. Out of it, 299 were males and 238 were females. Maximum number of patients i.e. 134 belonged to age group 31-40 years (72 males and 62 females). Least number of patients i.e. 5 were enrolled in age group $>70$ years (4 male and 1 female). Inappropriate demographic data was noted from 463 prescriptions, out of which, in 292 patients age was not mentioned and in 171 patient's sex was not mentioned.

Table 2: Table shows the details of diagnosis of the patient. Out of one thousand (1000) prescriptions, diagnosis was mentioned in only 396 prescriptions. Among the diagnosed patients, Psychosis was the commonest psychiatric disorder $(n=64,6.4 \%) .57(5.7 \%)$ patients were of anxiety. Other common complaints were schizophrenia $(n=52)$ and depression $(n=45)$.

Table 3: This shows prescribing frequency of psychotropic and different categories of drugs.

Table 1: Demographic profile of the patients.

\begin{tabular}{|ll|}
\hline Variables & Number $(\%)$ \\
\hline Age in years & \\
\hline $01-10$ & $52(9.8 \%)$ \\
\hline $11-20$ & $37(6.89 \%)$ \\
\hline $21-30$ & $119(22.16 \%)$ \\
\hline $31-40$ & $134(24.95 \%)$ \\
\hline $41-50$ & $103(19.18 \%)$ \\
\hline $51-60$ & $71(13.22 \%)$ \\
\hline $61-70$ & $16(2.98 \%)$ \\
\hline$>70$ & $5(0.93 \%)$ \\
\hline Sex & \\
\hline Male & $299(29.9)$ \\
\hline Female & $238(23.8)$ \\
\hline
\end{tabular}

Table 2: Diagnosis of patients.

\begin{tabular}{|ll|}
\hline Diagnosis & Number $(\%)$ \\
\hline Psychosis & $64(6.4)$ \\
\hline Anxiety & $57(5.7)$ \\
\hline Schizophrenia & $52(5.2)$ \\
\hline Depression & $45(4.5)$ \\
\hline Hypertension & $44(4.4)$ \\
\hline Seizure & $40(4.0)$ \\
\hline Ischemic Heart Disease & $15(1.5)$ \\
\hline Dementia & $11(1.1)$ \\
\hline Migraine & $09(0.9)$ \\
\hline Insomnia & $08(0.9)$ \\
\hline Acid Peptic Disease & $08(0.8)$ \\
\hline Bipolar Disorder & $07(0.7)$ \\
\hline Peripheral Neuropathy & $06(0.6)$ \\
\hline Diabetes Mellitus & $06(0.6)$ \\
\hline Hemiplegia & $05(0.5)$ \\
\hline Respiratory infection & $04(0.4)$ \\
\hline Angina & $04(0.4)$ \\
\hline Hypothyroidism & $03(0.3)$ \\
\hline Alcohol Withdrawal & $03(0.3)$ \\
\hline Pyogenic Meningitis & $02(0.2)$ \\
\hline Contusion & $02(0.2)$ \\
\hline Irritable Bowel & $01(0.1)$ \\
\hline Syndrome & $396(39.6)$ \\
\hline Total & \\
\hline
\end{tabular}


Table 3: Prescription of psychotropic and other drugs.

\begin{tabular}{|ll|}
\hline Categories & Number $(\%)$ \\
\hline Anti-anxiety agents & $361(36.1)$ \\
\hline Antidepressants & $130(13.0)$ \\
\hline Sedative Hypnotics & $104(10.4)$ \\
\hline Antipsychotic & $90(9.0)$ \\
\hline Anticonvulsants & $80(8.0)$ \\
\hline Miscellaneous & $73(7.3)$ \\
\hline Anti-hypertensives & $47(4.7)$ \\
\hline Antibiotics & $20(2.0)$ \\
\hline Antacids & $16(1.6)$ \\
\hline Antiemetics & $17(1.7)$ \\
\hline Analgesics & $27(2.7)$ \\
\hline Anti angina & $13(1.3)$ \\
\hline Anti diabetics & $12(1.2)$ \\
\hline Laxatives & $04(0.4)$ \\
\hline Diuretics & $03(0.3)$ \\
\hline Anti parkinsons & $03.3)$ \\
\hline
\end{tabular}

The prescribing frequency of anti-anxiety 361(36.1\%) and antidepressants $130(13 \%)$ were the most common categories of psychotropic drugs. The other psychotropic drugs prescribed in psychiatry OPD in descending order of frequency were Sedative Hypnotics 104(10.4\%), antipsychotics 90(9\%) and anticonvulsants $80(8 \%)$.

In other categories of drug viz. miscellaneous $73(7.3 \%)$, antihypertensive $47(4.7 \%)$ were the most commonly prescribed drugs.

Table 4 Shows the various combinations of psychotropic drugs which were prescribed. Total 223 patients received the combination regimes. The combination of Tricyclic antidepressants and benzodiazepines were most widely preferred by psychiatrists. The other combinations were of antipsychotic and central anticholinergic.

Table 5 depicts the Top Ten Brands among the psychotropic drugs. Lorpam( Lorazapam) was at the top table followed by Melzep (Clonazepam) and Alprax (Alprazolam).

Table 6 revealed various problems encountered in these prescriptions. Most common error found was diagnosis was not mentioned in (604). Other errors noted were absence of duration of treatment (306) and absence of age and sex.
Table 4: Prescribed combination of psychotropic drugs.

\begin{tabular}{|c|c|c|}
\hline $\begin{array}{l}\text { Brand } \\
\text { name }\end{array}$ & Generic name & Number \\
\hline Amixide & $\begin{array}{l}\text { Amitrptylline } \mathrm{HCl} 5 \mathrm{mg}+ \\
\text { chlordiazepoxide } 5 \mathrm{mg}\end{array}$ & 17 \\
\hline $\begin{array}{l}\text { Psycalm } \\
\text { plus }\end{array}$ & $\begin{array}{l}\text { Trifluperazine } \mathrm{HCl} 5 \mathrm{mg}+ \\
\text { trihexiphenydyl } \mathrm{HCl} 2 \mathrm{mg}\end{array}$ & 14 \\
\hline $\begin{array}{l}\text { Trinicamln } \\
\text { forte }\end{array}$ & $\begin{array}{l}\text { Chlorpromazine 50mg+ } \\
\text { Benzhexol } 2 \mathrm{mg}+ \\
\text { Trifluoperazine } \mathrm{HCl} 5 \mathrm{mg}\end{array}$ & 5 \\
\hline $\begin{array}{l}\text { Depsonil } \\
\text { DZ }\end{array}$ & $\begin{array}{l}\text { Imipramine } \mathrm{HCl} 25 \mathrm{mg}+ \\
\text { Diazepam } 2 \mathrm{mg}\end{array}$ & 5 \\
\hline Anzal Plus & $\begin{array}{l}\text { Propanolol } 20 \mathrm{mg}+ \\
\text { alprazolam } 0.25 \mathrm{mg}\end{array}$ & 5 \\
\hline $\begin{array}{l}\text { Trinicalm } \\
\text { plus }\end{array}$ & $\begin{array}{l}\text { Trifluperazine } \mathrm{HCl} 5 \mathrm{mg}+ \\
\text { trihexyphenydyl } \mathrm{HCl} 2 \mathrm{mg}\end{array}$ & 2 \\
\hline Benzyzine & $\begin{array}{l}\text { Trifluperazine } 10 \mathrm{mg}+ \\
\text { benzhexol } \mathrm{HCl} 2 \mathrm{mg}\end{array}$ & 2 \\
\hline Libotryp & $\begin{array}{l}\text { Chlodiazepoxide } 5 \mathrm{mg}+ \\
\text { Amitryptyline } \mathrm{HCl} \\
12.5 \mathrm{mg}\end{array}$ & 2 \\
\hline Omez - D & $\begin{array}{l}\text { Omeprazole }+ \\
\text { domperidone }\end{array}$ & 2 \\
\hline Epiphen & $\begin{array}{l}\text { Phenytoin sodium } 100 \mathrm{mg} \\
+ \text { phenobarbitone } 30 \mathrm{mg}\end{array}$ & 2 \\
\hline $\begin{array}{l}\text { Amlong- } \\
\text { AT }\end{array}$ & $\begin{array}{l}\text { Amlodepine } 5 \mathrm{mg}+ \\
\text { Atenolol 50mg }\end{array}$ & 2 \\
\hline Tancodep & Imipramine + diazepam & 1 \\
\hline Trizine-S & $\begin{array}{l}\text { Trifluperazine } \mathrm{HCl} 5 \mathrm{mg}+ \\
\text { triphexyphenydyl } \mathrm{HCl} \\
5 \mathrm{mg}\end{array}$ & 1 \\
\hline Tenoclor & $\begin{array}{l}\text { Atenolol } 25 \mathrm{mg}+ \\
\text { chlorthalidone } 12.5 \mathrm{mg}\end{array}$ & 1 \\
\hline Total & & 61 \\
\hline
\end{tabular}

Table 5: Top Ten Brands among the psychotropic drugs.

\begin{tabular}{|lll|}
\hline Brand Name & Generic Name & Number \\
\hline Lorpam & Lorazepam & 40 \\
\hline Melzep & Clonazepam & 28 \\
\hline Alprax & Alprazolam & 26 \\
\hline Oliza & Olanzepine & 25 \\
\hline Psycalm plus & $\begin{array}{l}\text { Trifluperazine }+ \\
\text { rihexyphenidyl }\end{array}$ & 22 \\
\hline Depsonil & Imipramine & 17 \\
\hline Alzolam & Alprazolam & 15 \\
\hline Amixide & $\begin{array}{l}\text { Amitryptilline }+ \\
\text { Chlodiazepexoide }\end{array}$ & 17 \\
\hline Trika & Alprazolam & 14 \\
\hline Restyl & Alprazolam & 14 \\
\hline Total & & 218 \\
\hline
\end{tabular}


Table 6: Problems observed in prescription.

\begin{tabular}{|ll|}
\hline Problem Description & Number \% \\
\hline Diagnosis not written & $604(60.4)$ \\
\hline Duration of treatment not written & $306(30.6)$ \\
\hline Age not written & $292(29.2)$ \\
\hline Sex not written & $171(17.1)$ \\
\hline
\end{tabular}

Figure 1 depicts total number of drugs per prescriptions. Maximum patient's i.e. in 324 patients two drugs were prescribed. 310 patients were prescribed three drugs, while 35 patients were given more than 6 drugs.

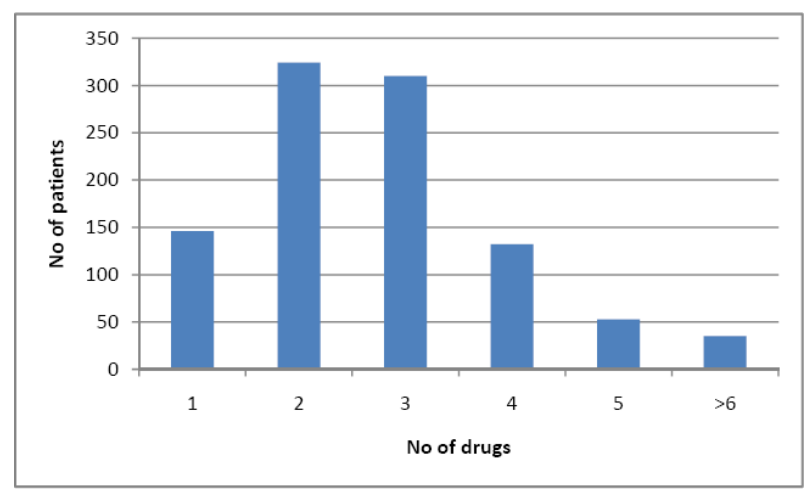

Figure 1: Number of drugs prescribed per prescription.

Figure 2 depicts the duration of treatment. In 266 patients, treatment was given for 16-30 days, 241 patients were on treatment for 1-15 days, while the drug therapy was continued for more than 90days in 25 patients.

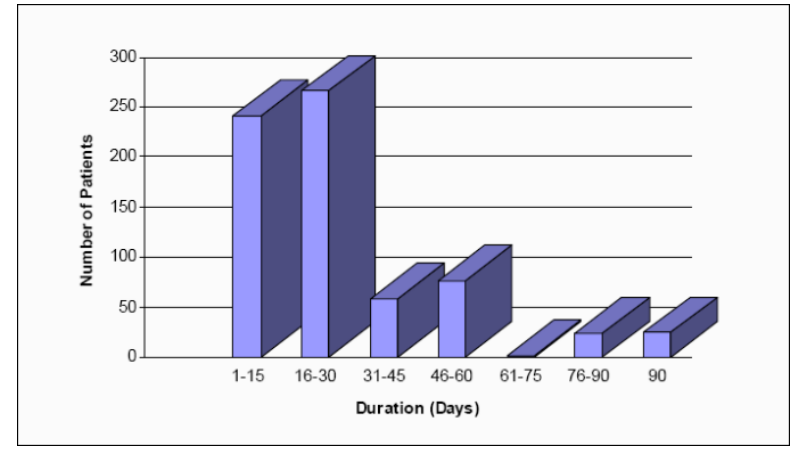

Figure 2: Duration of treatment.

Figure 3 shows drugs prescribed by Generic and Brand Name. Total 1647 were prescribed by brand name and only 47 drugs were by generic name.

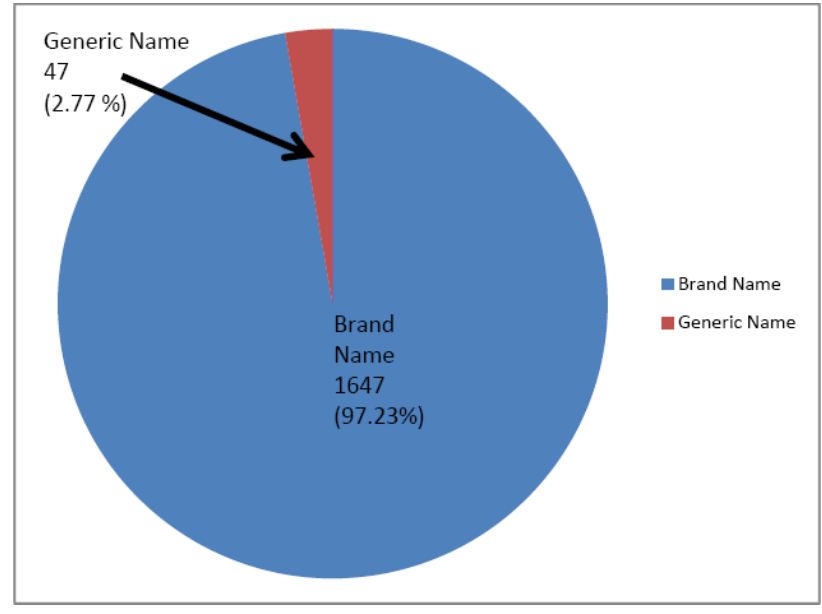

Figure 3: Drugs prescribed by Generic and Brand Name.

\section{DISCUSSION}

A prescription by a doctor may be taken as reflection of physician's attitude to the disease and the role of drug in its treatment. It also provides an insight into the nature of health care delivery system. ${ }^{9}$

This study indicates general trends in prescribing. As many as $1647(97.23 \%)$ drugs were prescribed by brand name. The aim of generic prescribing is to reduce cost through substitution of less expensive formulation for drugs prescribed by brand names. ${ }^{10}$ These are issues for concern and can be redressed to some extent by prescriber education.

The study elucidates inappropriate demographic data as in total 463 patients age, sex was not mentioned. In 604 $(60.4 \%)$ patients diagnosis was not mentioned. This indicates that majority of the prescribers do not adhere to the ideal pattern of the prescription writing. ${ }^{11}$ Over prescribing in $22 \%$ ( 4 or more) of the prescriptions indicates the increasing tendency of poly pharmacy. ${ }^{12}$

Average number of drugs per prescriptions is an important index of prescription audit. It is preferable to keep the mean number of drugs per prescription as low as possible since multiple drugs lead to increased risk of drug interaction. ${ }^{13}$

In this study, duration was not stated in 306 (30.6\%) prescriptions. This lapse on the part of physician needs to be brought to the notice of prescribers. It is important as many psychotropic drugs are potentially toxic and have to be prescribed for different periods, sometimes longer depending on individual patient.

Prescription order is an important transaction between the physician and patient. It brings into focus the diagnostic acumen and therapeutic proficiency of the physician with 
instructions for palliation or restoration of the patients health. ${ }^{14}$

In our study benzodiazepines were the most frequently prescribed class of psychotropic drugs. They are remarkably useful and efficacious in a wide range of conditions for short term or intermittent use. ${ }^{15}$ However, with long term use the adverse effects (memory impairment, depression, tolerance, dependence etc.) outweigh the benefits, which should be minimized by rational prescribing. Guidelines for the rational use of benzodiazepines recommend their use for short term (maximum for four week) or intermittent courses in minimum effective doses, to be prescribed only when symptoms are severe. ${ }^{16}$

Likewise prescribing prevalence of Alprazolam with different brand names was more than twice than that of other benzodiazepine observed in our study. Majority of studies with Alprazolam demonstrated efficacy for the treatment of anxiety disorders, panic disorders and depression. $^{17}$

Combination preparations of psychotropic drugs were prescribed in $61(6.1 \%)$ patients. Fixed dose combinations should be selected, only when the combination have proven advantage in therapeutic effect, safety or compliance over single compounds administered separately. ${ }^{18}$ The justification for such cause could not be ascertained in the present study.

The combination of tricyclic antidepressant with benzodiazepines was the most common combination prescribed by psychiatrist. The others were anti-psychotic with central anti-cholinergic.

Specific advice given to the patients was mentioned in 80 patients only.

\section{CONCLUSION}

Present study demonstrated that alprazolam, clonazepam and olanzapine are the commonly prescribed antipsychotropic drugs. Anti-anxiety drug (Benzodiazepines (BZD) usage was extensive as they were prescribed in almost all types of psychiatric illnesses. Rational use of BZD requires consideration and attention to dose and duration of usage as well as drug interactions with other psychotropic drugs.

Our study has some limitations. We focused on the first prescription and this may not necessarily reflect the true clinical situation. Depending on the response in many patients, further medications may have been added or deleted.

We did not document the dose and dosing schedule of the treatment given. We also did not evaluate factors like treatment adherence, availability of supervision, concerns of the patients about side effects, and adherence to treatment guidelines while prescribing.

\section{ACKNOWLEDGEMENTS}

The authors express their thanks to $2^{\text {nd }}$ MBBS students of Indira Gandhi Government Medical College, Nagpur for helping in data collection.

Funding: None

Conflict of interest: None

Ethical approval: The study protocol was approved by the Institutional Ethics Committee

\section{REFERENCES}

1. Victor I Rew. Mental Disorder, Harrisons Principle of Internal Medicine $17^{\text {th }}$ edn. 2008: 2710-2723.

2. Herbert E Ward and Albert J. Azzaro. Drugs used in Mood Disorders, Modern Pharmacology with clinical Application, $6^{\text {th }}$ edn, 2004: 385-396.

3. Bauer M, Monz BU, Montejo AL, Quail D, Dantchev N, Demyttenaerek,et al. Prescribing patterns of antidepressants in Europe: result from the factors influencing Depression Endpoints Research Study.Eur Psychiatry 2008; 23:66-73.

4. Smith S. Gender difference in antipsychotic prescribing .Int Rev Psychiatr Scand 2011; 123: 459-65.

5. Patterson HR.The problem of audit and Research, JR College Gen Pract 1986;36:196.

6. Stolley PD, Lasagne L. Prescribing pattern of Physician. J Chron Dis. 1969;22: 395-405.

7. Trivedi JK, Dayani M, Yadav VS, Rai SB. Antipsychotic drug prescription pattern for schizophrenia: observation from general hospital psychiatry unit. Indian J Psychiatry 2010;52:279.

8. Grover S, Avasthi A. Anti-psychotic prescription pattern: A preliminary survey of Psychiatrists in India. Indian J Psychiatry 2010;52: 279.

9. Laporte JR. Towards a healthy use of Pharmaceuticals. Development Dialogue.1988; 48-55.

10. Uppal R, Sharma PL. Prescribing trends in internal medicine International Journal of Clinical Pharmacology Therapy and Toxicology. 22(7) 375376,1984.

11. Budhiraja RD. Manual of Practical Pharmacy $2^{\text {nd }}$ edn. Bombay; Popular Prakashan. 1993;6.

12. Ansari KU. Rational drug therapy- Do we achieve it? Antiseptic 1987; 84: 357-60.

13. Nies SA, Spielberg SP. Principle of therapeutics In : Hardman IG, Limbard LE, Motinoff PB, Ruddon R Weas. Goodman \& Gilman's The Pharmacological basis of therapeutics $9^{\text {th }}$ edn. New York; Mc Graw Hill Press;1996: 43-62.

14. Benet LZ. Principle of prescription order writing and patients compliance. In: Goodman AG, Rall TW, NiesAS, Taylor P (eds). Goodman and 
Gilman's The pharmacological basis of therapeutics. $8^{\text {th }}$ ed. New York : Pergamon Press Inc. 1991: 1640.

15. Heather A. Toxicity and Adverse consequence of Benzodiazepine use.psychiatric Annals.1995;5:p 158-165. Available from: http: //www.benzo.org.uk /ashox.htmaccessed 17 feb 2011.

16. Ashton H. Guidelines for the rational use of Benzodiazepines. Drugs 1994;48:25-40.
17. Jonas JM, Cohon MS. A comparison of the safety and efficacy of Alprazolam versus other agents in the treatment of anxiety, panic and depression: a review of literature. J Clin Psychiatry 1993 Oct ; 54 Suppl 25-45; Discussion 46-8.

18. World Health Organization. The use of essential drugs WHO Technical Report Series 825.Geneva: World Health Orginzation; 1992.

doi:10.5455/2319-2003.ijbcp20131220

Cite this article as: Shamkuwar CA, Chakravorty AD, Shrivastava MP, Deshmukh R. Pattern of prescription and drug use in psychiatry out patient department of private practitioners of Central India. Int J Basic Clin Pharmacol 2013;2:777-82. 